\title{
POR UMA EPISTEMOLOGIA EMANCIPATÓRIA DA PROMOÇÃO DA SAÚDE
}

\author{
FOR AN EMANCIPATORY EPISTEMOLOGY OF HEALTH PROMOTION
}

Jairo Dias de Freitas $^{1}$
Marcelo Firpo Porto $^{2}$

Resumo Este trabalho discute as possibilidades e os limites da ação local com base nas contribuições do cientista social português Boaventura de Sousa Santos como aporte para a promoção da saúde em comunidades locais vulneráveis. Em especial, discute-se no artigo o conceito de espaços estruturais para entendermos as formas próprias de poder, de direito e de conhecimento da sociedade moderna diante de um capitalismo crescentemente globalizado, com suas contradições e alternativas de ação emancipatória. Tais reflexões fornecem, em nossa opinião, novas bases teórico-metodológicas para reorientar as práticas locais de saúde, ambiente e desenvolvimento. Para concluir, são consideradas as reflexões de Boaventura de Sousa Santos sobre a dupla ruptura epistemológica; e as de Paulo Freire a respeito do inédito viável para a proposição de algumas diretrizes na produção de conhecimentos e o desafio de pensarmos o futuro desses territórios junto aos jovens em contextos comunitários vulneráveis, nos quais situações-limite de sobrevivência e violência fazem parte do cotidiano e imitam ações emancipatórias.

Palavras-chave desenvolvimento local; promoção da saúde; comunidades vulneráveis; espaços estruturados; Boaventura de Sousa Santos.
Abstract This article discusses the possibilities and limits of local action based on the contributions of Portuguese social scientist Boaventura de Sousa Santos as a subsidy to promoting health in vulnerable communities. In particular, the article discusses the concept of structural spaces to understand the proper forms of power, law and knowledge of modern society confronted with increasingly globalized capitalism, with its contradictions and alternatives for emancipatory action. In our opinion, these reflections provide new theoretical and methodological foundations to redirect the local practices of health, environment and development. In sum, we consider Boaventura de Sousa Santos' reflections on the dual epistemological rupture; and those of Paulo Freire concerning the unprecedented viable to propose a few guidelines to produce knowledge and the challenge of thinking about the future of these territories among young people in vulnerable community settings, in which borderline survival conditions and violence are part of everyday life and imitate emancipatory actions.

Keywords local development; health promotion; vulnerable communities; structured spaces; Boaventura de Sousa Santos. 


\section{Introdução}

Discutem-se neste artigo, na forma de ensaio conceitual, as possibilidades e os limites da ação local com base na análise dos 'espaços estruturais' proposta pelo cientista social Boaventura de Sousa Santos (Santos, 2000). Busca-se contribuir para o debate entre posições críticas dos limites da ação local e da tendência ao ceticismo ante as iniciativas de transformação social e as que questionam o alcance e o caráter excessivamente normatizador e burocrático da proposta de promoção da saúde. Acreditamos que esse diálogo poderá contribuir para a compreensão dos limites e potencialidades das ações locais de promoção da saúde. Alinhamo-nos à visão de Pivetta e Porto (2010), ao defenderem uma promoção da saúde emancipatória. Esta envolveria um processo dinâmico e dialético de mediações e constituição de campos relacionais, cognitivos e éticos entre sujeitos individuais e coletivos, implicando uma produção compartilhada de conhecimentos e práticas favoráveis à constituição de espaços de conquistas de liberdade, de redução de vulnerabilidades socioambientais e de exercício dos direitos humanos fundamentais.

Nesse sentido, nosso intuito é entender os limites da ação local num território específico, e para isto, segundo Santos (2000), é necessária a compreensão do seu entorno maior, o sistema capitalista moderno, e dos espaços de constrangimentos, mas também de autonomias para a transformação fornecidas pelo sistema.

\section{Os espaços estruturais de Boaventura}

Um dos pontos-chave da análise de Boaventura é a crítica de um dos pilares da forma predominante de orientação das ações sociais, a concepção de desenvolvimento, um dos seus conceitos agregadores e de coesão.

A compreensão hegemônica a respeito do desenvolvimento é em geral muito limitada, confundindo-se com industrialização, crescimento econômico, aumento generalizado do consumo e da oferta de serviços e equipamentos públicos (Diegues, 1992). Os modelos de desenvolvimento alternativos ao hegemônico apresentados, de acordo com Boaventura, podem ainda estar calcados nos domínios de uma visão sociológica que enxerga o fenô-meno social de forma distanciada e estática, com leis gerais e imutáveis, o que pode resultar no reforço das desigualdades e exclusões, marcas do desenvolvimento clássico moderno. Por exemplo: grande parte das propostas para o desenvolvimento local se restringe ao aspecto econômico, objetivando determinar potencialidades de uma dada região para a sua inserção competitiva no mercado por meio de políticas focais e do aumento do 'capital social'. 
Uma visão restrita de desenvolvimento pode levar a uma ideia de inevitabilidade do modelo e de fatalidade das ações humanas. O que basicamente determina esse pensamento é a crença de que há apenas uma forma de desenvolvimento. A noção de desenvolvimento restrito e único possível relaciona-se ao que Boaventura identifica como instituições centrais na modernidade: o estado territorial, o direito estatal territorial e a ciência moderna, nascidos com o advento da sociedade moderna. O sucesso da ideia de desenvolvimento moderno se deve ao fato de que essas formas de poder, de direito e de conhecimento buscaram sobrepujar, com algum êxito, outras formas estabelecidas a partir de outros espaços chamados por Boaventura Santos de 'espaços estruturais'. Com a instalação da crise paradigmática identificada, principalmente, a partir do fim do século XX, essas outras formas de poder, de direito e de conhecimento não hegemônicas, sempre presentes nas sociedades, tornam-se mais evidentes (Santos, 2000).

Ao discutir as razões de escrever seu livro A crítica da razão indolente (Santos, 2000), Boaventura diz retornar a um conceito de Leibniz, que se insurgiu contra a ideia de que tudo é dado pelo destino. Nesta visão de mundo corroboradora de uma postura fortemente individualista das sociedades modernas de consumo, não há possibilidade de emancipação social (Santos, 2008a). O desafio é enfrentar realisticamente essa forma de pensamento e buscar alternativas de entender e transformar o mundo.

Boaventura desenvolve seu trabalho teórico com base no diálogo com autores contemporâneos como Bourdieu, Giddens e Foucault, os quais buscam avançar na compreensão crítica das sociedades capitalistas contemporâneas. Sua teoria provém da herança das duas tradições sociológicas derivadas de Marx e de Weber. Seu pensamento aproxima-se do de Habermas em pontos importantes, e não se pode dissociar sua obra de toda a tradição da teoria crítica formulada por membros da Escola de Frankfurt, para os quais haveria uma relação dialética entre teoria e práxis, distinta da ação pela ação. Embora Boaventura já tenha se autointitulado um 'pós-moderno de oposição' ante o que denomina de 'pós-moderno celebratório', autores com Avritzer (2002) o classificam como representante da modernidade tardia. Seus trabalhos sobre democracia têm auxiliado na reflexão de uma cidadania mundial, sendo sua visão de democracia participativa substancial para a construção de globalizações contra-hegemônicas, amplamente discutidas nos fóruns sociais mundiais.

De acordo com Boaventura, o paradigma da modernidade se assentaria em dois pilares: o pilar da regulação e o pilar da emancipação. O pilar da regulação se caracteriza por uma forma de obrigação política constituída pelo princípio do Estado, do mercado e da comunidade. A obrigação política do Estado é vertical e se dá entre cidadãos e o Estado. A regulação própria do mercado consiste em uma obrigação política horizontal individualista e 
antagônica entre parceiros. No princípio da comunidade, essa obrigação política é horizontal e solidária, e se processa entre membros da comunidade e da associação (Santos, 2000). Por sua vez, o pilar da emancipação é formado pela racionalidade cognitivo-instrumental da ciência, pela estéticoexpressiva das artes e literatura e a moral - prática do direito e da ética, definidas por Weber. Para Boaventura, a ciência e o direito, vistos como categorias emancipatórias no início da modernidade, tornaram-se, no seu transcorrer, categorias regulatórias hegemônicas a serviço das forças do mercado e das grandes corporações. Esse processo histórico resultou na formação do modelo da dupla delegação, que se concretiza ao colocar de forma exclusiva a competência técnico-científica nas mãos de especialistas e cientistas, e a político-administrativa nas mãos de políticos eleitos, funcionários dos estados e suas instituições. Nesse contexto, o cidadão é reduzido ao papel de mero eleitor, consumidor e 'usuário' de serviços e 'opções' políticas, ampliando-se a lógica instrumental de mercado para o conjunto da vida social.

A estratégia contra-hegemônica proposta envolve a reconstrução do polo da emancipação pelo resgate do concreto identificado com a construção de um senso comum emancipatório (Avritzer 2002, p. 41), buscando para isso, nas próprias representações da modernidade, espaços ainda presentes que apresentem potenciais de emancipação. Para Boaventura, a comunidade, uma das representações abertas e inacabadas da modernidade, seria um desses espaços.

Nesse contexto teórico e político, Boaventura propõe seis tipos de concreto principais existentes na modernidade, denominados por ele de espaços estruturais. Estes são os locais onde se manifestam formas de poder, de direito e de formas epistemológicas, e são por ele nomeados como: doméstico, produção, mercado, comunidade, cidadania e espaço mundial. Estes espaços estruturais são também denominados de "conjuntos de relações sociais" e de "matrizes das comunidades interpretativas principais existentes na sociedade" (Santos, 2000, p. 303). Os seis espaços estruturais são considerados:

campos tópicos, círculos argumentativos e auditórios unidos por conjunto de topoi locais. Cada espaço estrutural é um conjunto de argumentos, contra-argumentos e premissas de argumentação amplamente partilhadas, através das quais as linhas de acção e as interações definem sua pertença e a sua adequação dentro de um determinado campo tópico (Santos, 2000, p. 303).

Em relação aos topoi, Boaventura de Sousa Santos argumenta que:

Os topoi ou loci são "lugares comuns", pontos de vista amplamente aceites, de conteúdo muito aberto, inacabado ou flexível, e facilmente adaptável a diferentes contextos de argumentação (Santos, 2000, p. 99). 
Exemplos de topoi são as noções compartilhadas do justo e do injusto, e de quantidade. A ideia de desenvolvimento atrelado aos aspectos econômicos, em nossa opinião, consubstancia-se em um dos topoi que discutiremos adiante.

O domínio tópico é a matriz do senso comum de uma dada comunidade retórica. Haverá tantos domínios tópicos quantas comunidades interpretativas ou retóricas. Em determinada cultura ou sociedade, as diferentes comunidades não existem isoladamente: constituem-se como redes de comunidades. Os topoi mais gerais exprimem o que há de comum, pontos de vista partilhados. Cada comunidade é em si um domínio tópico. Os topoi desse domínio partilhados por outras comunidades da mesma rede constituem os topoi mais gerais.

Apesar de preservarem interações entre eles, os espaços estruturais são caracterizados por dinâmicas autônomas e a não hierarquia, embora se inter-relacionem e possam expressar diferentes formas de subordinação e hegemonia. Neste artigo, contudo, não podemos aprofundar a complexidade da proposta teórica apresentada, reconhecendo que os espaços estruturais apresentam dinâmicas e singularidades próprias, o que nos impediria tratar de forma similar espaços como o mundial e o doméstico sem cairmos em simplificações. O que gostaríamos de frisar é a perspectiva sistêmica e a hipótese 'desconstrutivista' de Boaventura de que tais espaços não seriam rigidamente hierarquizáveis e, portanto, teriam uma dinâmica autônoma, ainda que relativizada pelas interações entre eles. Nesse contexto, nas palavras de Boaventura, o espaço mundial é relativizado na sua condição de determinante de todos os outros:

Entre esses espaços, não há assimetrias, hierarquias ou primados que possam ser estabelecidos em geral, o que equivale a dizer que não há uma constelação "natural" ou "normal" de espaços estruturais. O desenvolvimento das sociedades capitalistas e o sistema mundial capitalista, como um todo, estão alicerçados em tais constelações, e não em qualquer dos espaços estruturais tomados individualmente (Santos, 2000, p. 314).

Ressalta-se que o encobrimento - seja por ignorância, seja por ocultação ou supressão - dessa constelação e a respectiva redução da política, do direito e do conhecimento são uma característica estrutural das sociedades capitalistas. Estas se caracterizam por:

uma supressão ideológica hegemônica do carácter político de todas as formas de poder, exceptuando a dominação; do carácter jurídico de todas as formas de direito, exceptuando o direito estatal; e do carácter epistemológico de todas as formas de conhecimento, exceptuando a ciência (Santos, 2000, p. 325).

Reproduzimos no Quadro 1, sinteticamente, os espaços estruturais e as respectivas formas de poder, direito e conhecimento propostos por Santos. 
Quadro 1

\begin{tabular}{|c|c|c|c|c|c|c|}
\hline $\begin{array}{l}\text { Dimensões } \\
\text { espaços } \\
\text { estruturais }\end{array}$ & $\begin{array}{l}\text { Unidade de } \\
\text { prática social }\end{array}$ & Instituições & $\begin{array}{l}\text { Dinâmica de } \\
\text { desenvolvimento }\end{array}$ & $\begin{array}{l}\text { Forma de } \\
\text { poder }\end{array}$ & $\begin{array}{l}\text { Forma de } \\
\text { direito }\end{array}$ & $\begin{array}{l}\text { Forma } \\
\text { epistemológica }\end{array}$ \\
\hline $\begin{array}{l}\text { Espaço } \\
\text { doméstico }\end{array}$ & $\begin{array}{l}\text { Diferença sexual } \\
\text { e geracional }\end{array}$ & $\begin{array}{l}\text { Casamento, família } \\
\text { e parentesco }\end{array}$ & $\begin{array}{l}\text { Maximização da } \\
\text { afetividade }\end{array}$ & Patriarcado & $\begin{array}{l}\text { Direito } \\
\text { doméstico }\end{array}$ & $\begin{array}{l}\text { Familismo, } \\
\text { cultura familiar }\end{array}$ \\
\hline $\begin{array}{l}\text { Espaço da } \\
\text { produção }\end{array}$ & $\begin{array}{l}\text { Classe e natureza, } \\
\text { enquanto natureza } \\
\text { capitalista }\end{array}$ & Fábrica e Empresa & $\begin{array}{l}\text { Maximização do } \\
\text { lucro e da degradação } \\
\text { da natureza }\end{array}$ & $\begin{array}{l}\text { Exploração } \\
\text { e natureza } \\
\text { capitalista }\end{array}$ & $\begin{array}{l}\text { Direito da } \\
\text { produção }\end{array}$ & $\begin{array}{l}\text { Produtivismo, tecno- } \\
\text { logismo, formação } \\
\text { profissional e } \\
\text { cultura empresarial }\end{array}$ \\
\hline $\begin{array}{l}\text { Espaço de } \\
\text { mercado }\end{array}$ & $\begin{array}{l}\text { Cliente - } \\
\text { consumidor }\end{array}$ & Mercado & $\begin{array}{l}\text { Maximização da } \\
\text { utilidade e da merca- } \\
\text { dorização das neces- } \\
\text { sidades }\end{array}$ & $\begin{array}{l}\text { Fetichismo das } \\
\text { mercadorias }\end{array}$ & $\begin{array}{l}\text { Direito da } \\
\text { troca }\end{array}$ & $\begin{array}{l}\text { Consumismo e } \\
\text { cultura de massa }\end{array}$ \\
\hline $\begin{array}{l}\text { Espaço da } \\
\text { comunidade }\end{array}$ & $\begin{array}{l}\text { Etnicidade, raça, } \\
\text { nação, povo, religião }\end{array}$ & $\begin{array}{l}\text { Comunidade, } \\
\text { vizinhança, região, } \\
\text { org. populares de } \\
\text { base, Igrejas }\end{array}$ & $\begin{array}{l}\text { Maximização da } \\
\text { identidade }\end{array}$ & $\begin{array}{l}\text { Diferenciação } \\
\text { desigual }\end{array}$ & $\begin{array}{l}\text { Direito da } \\
\text { comunidade }\end{array}$ & $\begin{array}{l}\text { Conhecimento local, } \\
\text { cultura da comunidade } \\
\text { e tradição }\end{array}$ \\
\hline $\begin{array}{l}\text { Espaço da } \\
\text { cidadania }\end{array}$ & Cidadania & Estado & $\begin{array}{l}\text { Maximização } \\
\text { da lealdade }\end{array}$ & Dominação & $\begin{array}{l}\text { Direito territorial } \\
\text { (estatal) }\end{array}$ & $\begin{array}{l}\text { Nacionalismo educacional } \\
\text { e cultural, cultura cívica }\end{array}$ \\
\hline $\begin{array}{l}\text { Espaço } \\
\text { mundial }\end{array}$ & Estado-nação & $\begin{array}{l}\text { Sistema interestatal, } \\
\text { organismos e assoc. } \\
\text { intern., tratados } \\
\text { internacionais }\end{array}$ & $\begin{array}{l}\text { Maximização } \\
\text { da eficácia }\end{array}$ & Troca desigual & Direito sistêmico & $\begin{array}{l}\text { Ciência, progresso } \\
\text { Universalístico, cultura } \\
\text { global }\end{array}$ \\
\hline
\end{tabular}

Fonte: Santos (2000, p. 273).

A proposta teórica de Boaventura Santos implica novas práticas sociais que têm por tarefa central

promover, em cada um dos seis conjuntos de relações sociais, através da retórica dialógica, a emergência de topoi e de argumentos emancipatórios ou de sensos comuns contra-hegemônicos, que irão expandir-se a par dos auditórios argumentativos criados a sua volta, para se tornarem mais tarde conhecimentos-emancipação hegemônicos (Santos, 2000, p. 308).

A emancipação se dá com uma tópica da emancipação, por meio do pressuposto de que processos sociais, políticos e de produção de conhecimentos contra-hegemônicos permitirão a substituição das relações sociais 
regulatórias por outras de caráter emancipatório. Em outras palavras, por meio da ideia de que ações localizadas produzidas por diferentes sujeitos em distintos espaços possam ir se articulando por meio de ações sociais que possibilitem a formação de coletivos mais amplos em direção a uma sociedade mais justa e democrática por enfrentar o importante dilema contemporâneo 'igualdade versus diferença', e expresso por Boaventura em seu célebre aforismo: "Temos o direito a ser iguais quando a diferença nos inferioriza; temos o direito a ser diferentes quando a igualdade nos descaracteriza" (Santos, 2010, p. 462).

Identificar dispositivos de regulação e de emancipação social permite, nesta proposta teórica, refletir sobre o sentido e as possibilidades da ação local e comunitária, o que é de grande importância para ações de promoção da saúde. Reconhecem-se poderes, conhecimentos e direitos locais que fogem de uma lógica de determinação absoluta nas leituras das sociedades capitalistas, seja como adesão inevitável a esse modelo, seja como visão crítica pessimista e saudosista a partir dos ideais utópicos e revolucionários construídos nos séculos XIX e XX. O Quadro 2 apresenta um conjunto de exemplos dos tópicos ou temáticas que caracterizam as relações sociais em cada espaço estrutural, seja em sua forma dominante, seja como potencial emancipatório.

Quadro 2

\begin{tabular}{lll}
\hline Espaços estruturais e exemplos de tópicos dominantes ou emancipatórios \\
\hline Espaço & $\begin{array}{l}\text { Tópico relações } \\
\text { sociais dominantes }\end{array}$ & $\begin{array}{l}\text { Tópico relações } \\
\text { sociais emancipatórias }\end{array}$ \\
\hline Doméstico & Patriarcal & Libertação da mulher \\
Comunidade & Chauvinista & Cosmopolita \\
Cidadania & Tópica do norte & Temocraciacia forte do sul \\
Espaço mundial & Capitalista & Eco-socialista \\
Produção & Consumismo fetichista & Necessidades fundamentais \\
& e satisfações genuínas \\
\hline
\end{tabular}

Fonte: Os autores, a partir de Santos (2000). 
Em síntese, Boaventura Santos entende a realidade social dividida em seis espaços estruturais; identifica outras formas de poder, de direito e de conhecimento não evidentes como o poder territorial, o direito estatal e a ciência moderna; e desloca o entendimento dos processos sociais às questões relativas ao poder. Segundo a ideia de que existe uma autonomia, mesmo relativa, entre os vários espaços estruturais e uma constelação entre poderes e formas de conhecimento, assume que estes podem ser reforçados ou neutralizados mutuamente no jogo dinâmico e complexo que é a sociedade em transformação.

\section{Os espaços estruturais de Boaventura no contexto da saúde, do ambiente e das ações locais}

Muitas das reflexões acerca da saúde, do ambiente e do desenvolvimento têm reduzido suas considerações, privilegiando apenas um dos espaços estruturais que Boaventura nomeia - o espaço da produção, notadamente um dos maiores responsáveis pela precariedade das condições presentes de saúde e do ambiente (Rigotto, 2003). Entretanto, esse espaço representa parte da sociedade, ainda que hegemônico dentro das sociedades modernas. Há poderes, formas de conhecimento e de direito que extrapolam o domínio da produção, como mostra o Quadro 1. Esta observação é de particular importância para a compreensão da obra de Boaventura, que busca articular as duas principais contradições históricas do capitalismo: a primeira, que influenciou as principais análises, visões críticas e rupturas sociais desde o século XIX até a segunda metade do século XX, estão associadas com as condições de trabalho (forças de produção), tendo como principais protagonistas os trabalhadores expropriados da sua produção, sendo, portanto, de grande significado os conceitos de alienação e mais-valia.

Por sua vez, a segunda contradição, que envolve a passagem de uma sociedade de massas para uma sociedade de consumidores e cresce em importância com as transformações sociais, financeiras e tecnológicas do capitalismo contemporâneo das últimas quatro décadas, relaciona-se menos às condições de trabalho e mais às condições de produção e à produção das condições (O'Connor, 2001, p. 163), o que incluiria as problemáticas dos direitos humanos, ambientais, de gênero e étnicas, dentre outras. Dessa forma, o protagonismo principal das transformações sociais não mais pertenceria ao proletariado, como na fase anterior, mas sim aos coletivos contra-hegemônicos organizados em torno de suas próprias agendas de mudança social, como ambientalistas, feministas, povos tradicionais, movimentos culturais das periferias urbanas, dentre outros (Schütz, 2008, p. 2).

Na democracia liberal hegemônica, entretanto, as práticas de governança buscam manter fragmentados tais grupos e suas demandas, confinando a 
solução de conflitos às instâncias formais do modelo da dupla delegação. Neste contexto, um desafio teórico e político central seria o avanço de uma compreensão crítica e articuladora da realidade e seus vários movimentos contra-hegemônicos, de maneira a permitir a formação de coletivos mais amplos e transformações sociais que resgatassem a perspectiva emancipatória da modernidade. A obra de Boaventura e sua inserção política nos fóruns sociais mundiais fazem parte desse desafio.

Ampliando-se as reflexões a partir dos espaços estruturais da sociedade capitalista (Santos, 1989, 2000), pode-se afirmar que o espaço da produção é apenas um dos seis espaços estruturais. Cada espaço possui uma forma própria de conhecimento, de direito e de poderes. Desenvolvimento, saúde e ambiente inseridos no contexto da produção estarão referenciados à lógica deste. Considerando-se outro espaço como o da cidadania, os três termos terão significados distintos. A forma de compreensão a respeito da relação entre desenvolvimento, saúde e ambiente em cada um dos espaços estruturais corresponde ao conjunto de representações sociais acerca destes.

À guisa de exemplo, Vianna e Elias (2007) discutem as dimensões da saúde como direito, bem econômico e espaço de acumulação de capital, que geram três movimentos simultâneos - desmercantilização do acesso, mercantilização da oferta e formação do complexo industrial da saúde. Estes convivem atualmente de forma complexa e conflituosa em um mesmo sistema de saúde, e podem ser esquematizados como a seguir:

1. A saúde como direito $\rightarrow$ desmercantilização do acesso $\rightarrow$ sistemas de proteção social.

2. A saúde como bem econômico $\rightarrow$ mercantilização da oferta $\rightarrow$ assalariamento dos profissionais, formação de empresas médicas e intermediação financeira (planos).

3. A saúde como espaço de acumulação de capital $\rightarrow$ formação do complexo industrial da saúde $\rightarrow$ globalização e financeirização da riqueza.

A dimensão da saúde como direito remete ao espaço estrutural da cidadania. Já a saúde como bem econômico e como acumulação de capital se desloca para constelações entre o espaço do mercado e o espaço da produção. Ou seja, essas dimensões se referem a espaços estruturais distintos, interdependentes, mas autônomos. A lógica de cada dimensão se estabelece a partir do espaço estrutural em que se localiza. As possíveis formas conflituosas traduzem a disputa de diferentes projetos de sociedade em curso e que fazem parte do jogo democrático, embora na democracia liberal hegemônica haja o encobrimento, o controle e a despolitização dos movimentos coletivos contra-hegemônicos. É importante entender os significados da saúde e do ambiente em cada um dos espaços para, a partir daí, buscar formas de concebê-los de maneira mais ampla, em contraposição à forma restritiva de cada espaço. 
Boaventura contribui no entendimento a respeito da autonomia dos espaços estruturais e das possibilidades da ação local, o que é visto como fundamental para se romper com a visão hegemônica de um modelo único de desenvolvimento. Ou ainda para que transformações somente ocorram a partir de mudanças estruturais que provenham de níveis de organização da sociedade desvinculada do cotidiano. Para Boaventura, a ideia de dependência (não autonomia) entre os espaços está relacionada ao entendimento cristalizado de uma única forma de direito, de poder e de conhecimento, encobrindo ou suprimindo outras possibilidades. Tal encobrimento de caráter ideológico ocorreu utilizando-se de retóricas de legitimação, como no caso da ciência, cuja capacidade de predição foi amplamente utilizada, fazendo com que outros saberes fossem perdendo importância.

Boaventura identifica como uma das representações mais abertas ou inacabadas no domínio da regulação (Mercado, Estado e Comunidade) o próprio 'princípio da comunidade'. Por isso, crê ser o "mais bem colocado para instaurar uma dialéctica positiva com o pilar da emancipação" (Santos, 2000, p. 75). Entretanto, a comunidade, como um espaço estrutural autônomo, solicita estratégias específicas para sua intervenção por apresentar formas próprias de poder, de direito e de conhecimento. No caso das ações de promoção da saúde, essas formas próprias não podem ser negligenciadas, sob pena de tornarem as ações pouco ou nada eficazes. Por exemplo: o espaço da cidadania é o mais próximo, porém a utilização de formas de conhecimento mais próprias desse espaço, ao serem elas empreendidas no espaço comunitário, pode gerar conflitos, por carecerem do 'senso comum comunitário' necessário para sua consecução.

A formulação de Boaventura auxilia no entendimento dos significados e posturas dos grupos que compõem a sociedade. Reafirma a complexidade do agir humano, auxiliando na superação de posições simplistas diante do desafio de promover a saúde e a qualidade de vida, não menosprezando saberes populares ante o conhecimento dito científico. Fica implícito em Boaventura que a razão dialógica é a que deve prevalecer sobre a razão instrumental, o que está de acordo com vários princípios da Saúde Coletiva e da produção compartilhada de conhecimentos. Os espaços estruturais e os seus desdobramentos se alinham com 'promover a saúde com' e não 'promover a saúde para'. Coadunam-se com a busca pela expansão dos princípios democráticos, entre eles qualificando a participação, a responsabilidade e a solidariedade. Essa busca se evidencia pelo projeto de Boaventura em analisar experiências de participação democráticas em 'países do sul' aparentemente sem tal tradição e que enriquecem o debate justamente por realizarem a emergência de saberes e práticas contra-hegemônicos (Santos, 2008b); Pereira e Carvalho, 2008; Marques, 2008). Tem também o mérito de ampliar as análises centradas na dicotomia Estado/sociedade civil, que, 
como toda teoria, possibilita análises importantes, mas também cria restrições e limites no entendimento de fenômenos que se vêm observando na sociedade. Entre estes, podemos destacar os conflitos socioambientais e sua regulação, espaços estruturais de Boaventura que, segundo Reis (2007), podem contribuir para uma análise menos dogmática e mais propositiva.

\section{Contribuições no campo da saúde}

A ampliação para os espaços estruturais aumenta o leque de interpretações e abre perspectivas de ações emancipatórias da forma hegemônica de se entender e exercer poderes. Tal proposta se alinha a diversos autores da Saúde Coletiva que localizam nas falas populares não estados de ignorância, mas de saberes (Valla, 2000; Minayo, 1998; Rozemberg, 2007).

Minayo (1998), por exemplo, ao estudar as representações sociais de um grupo de moradores de favela, sugere que a ideia de saúde descrita por estes procura ser de uma forma abarcante, buscando uma totalidade que o termo apresenta devido a sua estreita relação com a própria vida cotidiana. Consubstancia-se numa visão de "saúde-doença" que é "pluralista, ecológica e holística" (Minayo, 1998, p. 363), diferente da racionalização conceitual da ciência que insiste em evidenciá-la de forma simplista e fragmentada pelo modelo biomédico ou pela dicotomia saúde-doença unicausal.

Em outra publicação, Valla (2000) problematiza a dificuldade da academia em entender a fala das classes populares, principalmente em aceitar que estas são produtoras de conhecimento. Outra questão importante, segundo o mesmo autor, está na tentativa de se uniformizar grupos de locais diversos, com culturas diferentes e uma relação diversa com o capital, como as apresentadas por operários, moradores de comunidades das periferias urbanas e camponesas. Isto se reflete na debilidade de compreensão que Valla bem afirma ser da academia, por não se entender a cultura popular como "conhecimento acumulado, sistematizado, interpretativo e explicativo" (Valla, 2000, p. 30). Ao inverter as posições e reafirmar que a crise de interpretação é nossa, Valla recoloca a centralidade dos sujeitos, suas histórias, contextos e culturas. Coloca-se em evidência, dessa forma, a inversão anterior produzida pela razão metonímica que reivindicou ser, na modernidade, a única forma de racionalidade, cujo reducionismo consiste em circunscrever toda a riqueza de significados da vida em teorias instrumentais, uniformizandose condutas e comportamentos.

A postura problemática de autorreferência, nesse caso entre centro e periferia, é discutida por Rozemberg (2007), pois cria uma 'cacofonia' e faz com que os discursos dos 'de fora', como são chamados quaisquer que não sejam da comunidade analisada - rural, no caso da autora -, não tenham 
significado para aqueles que se veem como centro e que se estruturam em torno do trabalho, da família e da comunidade. A tentativa de constelação entre a ciência, o saber hegemônico e os sensos comuns em uma comunidade rural é retratada pela autora. Uma dessas tentativas se dá pela busca de legitimação por parte do saber popular ao renomear plantas medicinais pelos nomes dos medicamentos, como pé de 'novalgina' ou 'gelol', buscando uma identidade com o conhecimento científico. Outra forma se dá pelo viés do consumo, inclusive de medicamentos, que "exercem fascínio inequívoco de progresso e de mudança de status social" (Rozemberg, 2007, p. S103). Revela, portanto, uma relação com o espaço estrutural do consumo e com o fetiche da mercadoria, conceito cunhado por Marx ao analisar o capitalismo. As considerações descritas são percebidas por Rozemberg (2007) como perda da autonomia local, devido à globalização, mecanismo que Boaventura descreve bem.

Ainda sobre a disseminação de informações científicas em áreas rurais, constata-se o efeito mais perverso da transmissão linear de conhecimentos. Além do pouco ou nenhum efeito de mobilização por parte da população que recebe informações descontextualizadas e fragmentadas, pode-se, com base nessa transferência de informação, suscitar comportamentos equivocados por parte da comunidade - por exemplo, ao se identificarem 'comportamentos de risco' com doenças de veiculação hídrica à quase totalidade da experiência de vida dos moradores (lavoura, rio, lago, charque). Assim, informações descontextualizadas acabam por reforçar uma tendência de se achar que nada pode ser feito, de se atribuir um caráter aleatório à doença como fatalidade geograficamente determinada ou fenômeno acidental (Rozemberg, 2007).

\section{Articulando mudanças nos espaços estruturais}

Assim como formas de dominação não se restringem ou não estão circunscritas a um dado espaço estrutural, mas exprimem o resultado de uma constelação que reforça uma hierarquia de poderes, direitos e saberes, as soluções utópicas descontextualizadas e não resultado de um consenso traduzem-se igualmente em formas de cristalização e engessamento do futuro, o que dificulta a emergência de possibilidades democráticas. Exemplos de cristalização são as interpretações de processos de conflitos socioambientais à luz de teorias estruturalistas que enxergam nesses conflitos apenas um sintoma de uma 'patologia' social e não o sentido positivo de possibilidade de mudança para estados mais democráticos. Assim, reduz-se a análise dialética para estruturas sociais e históricas que se distanciam do espaço cotidiano das comunidades e pessoas. Daí a importância de serem valorizadas e ressig- 
nificadas experiências em curso que assumam como legítimos diversos saberes populares e práticas comunitárias incorporadas na promoção da saúde, sem que isso signifique uma simples subtração temporária do saber científico hegemônico, mas sim confrontações entre senso comum e saber científico que permitam rupturas e avanços.

A questão do conflito também é analisada por Dahrendorf (1981). Para o autor, "das duas questões básicas da análise sociológica - o que mantém unidas as sociedades? E o que as impulsiona para frente? -, predominou a primeira nestes últimos decênios" (Dahendorf, 1981, p. 134), embora o estudo do conflito social esteja associado justamente à segunda questão. De forma semelhante, Silva (2004) entende que, em regimes democráticos, o conflito deve ser estimulado abrindo espaços para reivindicações de grupos que lutam por direitos, igualdade ou mesmo pelo reconhecimento de diferenças, sendo esta uma busca permanente a ser incorporada por formas democráticas de regulação. Há o contraponto importante apresentado por Silva, que é o fato de a regulação também fazer com que as hierarquias que permanecem sejam legitimadas e vistas como lícitas. É, portanto, nessa tensão que a sociedade se desenvolve.

Um aspecto limitante nas estratégias de ação se refere à dificuldade para a mudança nos sensos comuns. As articulações entre os espaços são igualmente necessárias para que haja a mudança em todos eles. Portanto,

Essas lutas de conhecimento devem ser travadas em todos os seis conjuntos de relações sociais. Tal como o conhecimento-regulação, o conhecimento-emancipação também só funciona em constelações de conhecimentos. Negligenciar este facto equivale a correr o risco de a retórica emancipatória, conquistada numa das formas epistemológicas, se constelar "ingenuamente", com a retórica regulatória de outra forma epistemológica (Santos, 2000, p. 308).

Assim, é necessário romper com o modelo da dupla delegação para que, nas palavras de Boaventura, uma 'epistemologia da cegueira' seja suplantada por uma 'epistemologia da visão'.

Tão importante quanto reforçar a possibilidade e a efetividade das ações locais, entendendo-as como espaços de práticas sociais autônomas e não hierarquizáveis, é perceber os limites dessas ações, articulando-as com outros tópicos emancipatórios em diferentes espaços estruturais. Isso economizaria esforços, focando-se as expectativas no que é realmente factível, ao mesmo tempo em que ampliaria as formas de atuação ao conjugar dialeticamente práticas locais emancipatórias com mudanças em outros espaços estruturais e fóruns, como as instituições no âmbito da academia, do direito, da regulação e da política, bem como entre distintos territórios por meio de redes sociais. Essa consideração suscita questões importantes para a investigação: 
como se traduz, na prática, essa dificuldade da luta que se dá em arenas distintas? Como interferir em outros espaços? Invertendo a mão, poderíamos nos indagar como os topoi gerais se consolidaram nos diversos espaços estruturais, o que nos daria preciosas pistas para trilhar o caminho contra-hegemônico da solidariedade e de práticas de promoção da saúde emancipatórias. A relativização proposta pela teoria dos espaços estruturais possibilita reafirmar, de forma consciente, a pertinência de ações em cada um desses espaços, ao mesmo tempo que esclarece a existência de limites para tal ação. Ambas as conclusões são de muita importância para aqueles que trabalham com populações e comunidades vulnerabilizadas - sejam elas de favelas, sejam camponesas, indígenas ou quilombolas - por processos históricos excludentes e discriminadores. Tal perspectiva permite nos afastar tanto de um estado de inércia de posições estruturalistas que afirmam não ser possível fazer nada localmente quanto da ingenuidade inversa que sustenta serem as ações locais (auto)suficientes para as transformações necessárias.

\section{A ação local no contexto da dupla ruptura epistemológica de Boaventura}

Retomando a noção da dupla delegação hegemônica nas sociedades capitalistas contemporâneas, um desafio importante seria criar as condições para que se opere uma dupla ruptura epistemológica, uma 'ruptura da ruptura', que transforme de forma articulada senso comum e conhecimento científico a partir da solidariedade e de processos emancipatórios. Em outras palavras, trata-se, como propõem Santos $(2007,2008$ b) e Nunes (2007), de reconhecer e enfrentar uma

epistemologia da cegueira que "exclui", ignora, silencia, elimina e condena à nãoexistência epistêmica tudo o que não é susceptível de ser incluído nos limites de um conhecimento que tem como objectivo conhecer para dominar e prever (Santos, 2008b, p. 49).

Em obras mais recentes, Boaventura vem consolidando como proposta alternativa à constituição de uma 'ecologia dos saberes' uma 'epistemologia da visão', que reconheça as ausências, emergências e possibilidades de outros futuros com base nas experiências e nos processos em curso fora do universo eurocêntrico dos países centrais, das lógicas de mercado e regulatórias baseadas na ciência hegemônica. Portanto, se queremos criar novas bases éticas, políticas e epistemológicas para o desenvolvimento humano, torna-se necessário estabelecer e ampliar diálogos que incluam as singularidades e contribuições de países da América Latina, África e Ásia em sua relação com as discussões em curso sobre democracia e alternativas de 
desenvolvimento numa sociedade cada vez mais globalizada e em crise, e diálogos que reflitam sobre essas singularidades e contribuições.

Do ponto de vista dos processos sociais mais recentes, uma nova forma de enfrentar a ambivalência entre regulação e emancipação encontra-se presente, segundo Boaventura, nos novos movimentos políticos que se articulam em espaços como o Fórum Social Mundial. Esses movimentos sistematicamente se recusam a seguir antigas clivagens e dilemas que marcaram as ações políticas em vários países no período pós-colonial, e que resultaram do legado histórico das forças sociais que produziram lutas políticas e projetos utópicos nos últimos duzentos anos. Entre os dilemas que os novos movimentos sociais vêm buscando superar, são citados: reforma ou revolução; socialismo ou emancipação social; o Estado como inimigo ou como aliado potencial; as lutas nacionais ou globais; a ação direta ou institucional; o princípio da igualdade ou o princípio do respeito pela diferença. Muitos movimentos e organizações se recusam a assumir de forma simplista, binária ou maniqueísta uma posição ou outra, o que possibilita uma enorme constelação de alternativas de ações coletivas e em redes sociais. Assim, são produzidas ao mesmo tempo contradições, mas também novas possibilidades de articulação e alianças estratégicas a partir do momento em que os movimentos e organizações se libertam de atuarem sempre em consenso sobre todos os pontos, com clivagens de baixa intensidade.

Ao analisar criticamente a obra de Boaventura, Peter Wagner (2004) percebe duas versões de conhecimento em sua 'agenda', denominadas de 'versão forte e versão fraca'. A versão forte preconiza "uma alternativa ainda não existente capaz de resolver todos os problemas", podendo ser classificada em termos de tradição crítica utópica no sentido "de alcançável assim que os obstáculos forem removidos". A versão fraca, também utópica, mas como algo mais processual e próximo da vivência cotidiana, está "sempre a lutar para aceder à existência". A versão fraca aponta para uma ruptura que vislumbra uma pluralidade de perspectivas, uma diversidade de conhecimentos. Uma nova situação, por conseguinte, na qual o "conhecimento surge sob uma multiplicidade de formas" (Wagner, 2004.)

Aproximando-se esta discussão ao campo da Saúde Coletiva, propostas de desenvolvimento no nível local, como as preconizadas pela promoção da saúde no nível comunitário, podem se articular com a chamada 'versão fraca', desde que integradas a processos de emancipação e solidariedade. Dialeticamente, em nossa compreensão, tais propostas poderão trilhar o caminho mais realista para a construção de alternativas que poderão vir a consubstanciar novos futuros ainda utópicos de desenvolvimento e organização da sociedade em seus diferentes espaços estruturais. Tal visão vai além das propostas de caminho para o conhecimento, tornando mais visíveis também os obstáculos. Propõe que as práticas científicas sejam postas em outro lugar, 
relativizando suas reivindicações de certeza epistêmica na comunicação com outras formas de conhecer.

Pensar o conhecimento atrelado à vida dos sujeitos tem relevância e justificativa, à medida que cada comunidade possui um conjunto de fatores que as torna particular. No dizer de Milton Santos, "cada lugar é, ao mesmo tempo, objeto de uma razão global e de uma razão local, convivendo dialeticamente" (Santos, 1997, p. 273). As generalizações com reduções descontextualizadas da realidade das pessoas, marcas da ciência moderna, mascaram as necessidades comunitárias, dificultando formas mais dialógicas e democráticas de entendimento e inviabilizando as mudanças.

\section{A práxis freiriana e suas articulações com o pilar da emancipação em Boaventura}

A formulação dos espaços estruturais em uma situação concreta nos auxilia a pensar e propor encaminhamentos de questões em que a coletividade se coloca em diferentes contextos e territórios alvos de ações de promoção da saúde, sejam eles os territórios urbanos das periferias e favelas, sejam os dos assentamentos rurais envolvendo populações camponesas e propostas agroecológicas, ou ainda aqueles que envolvem populações tradicionais, como indígenas e quilombolas, para citar alguns exemplos relevantes na realidade brasileira. Acreditamos que o trabalho em saúde e ambiente orientado pela teoria de Boaventura pode se articular com o pensamento de Paulo Freire e sua visão de esperança, entendida como uma necessidade ontológica para a existência humana. Junto com o sonho, nutre a luta para melhorar a vida, mas ela precisa estar aliada à prática cotidiana, pois, "enquanto necessidade ontológica, a esperança precisa da prática para tornar-se concretude histórica" (Freire, 1994, p. 11). Para Freire, conhecer as razões históricas e econômicas que explicam a desesperança é fundamental para ultrapassá-la. Ele aponta então para o que chamou de construção do 'inédito viável' (Freire, 1981, 1983, 1996). Presente desde os primeiros escritos de Freire, esta categoria relaciona-se à compreensão da história como possibilidade decorrente de uma posição utópica que se opõe a uma visão fatalista da realidade (Freitas, 2005). Freire destaca a importância da subjetividade, da relação consciência-mundo e das possibilidades de transformação da realidade. Nos seus escritos, observa-se a aplicação intransigente da dialeticidade na história e na existência humana, levando a um pensamento tributário às mudanças e à necessidade de permanente construção da vida:

O futuro com que sonhamos não é inexorável. Temos de fazê-lo ou não virá da forma como mais ou menos queríamos. É bem verdade que temos de fazê-lo não 
arbitrariamente, mas com o concreto que dispomos e mais com o projeto, com o sonho que lutamos (Freire, 1994, p. 102).

Longe de estar consolidada, a razão de ser do humano é humanizar-se, ser mais, num processo dialético e histórico.

A crítica ao conhecimento regulatório hegemônico da ciência pode ser reconhecida na obra de Freire (1983). Entretanto, o educador alerta para os limites do que chamou de 'consciência real' como aquela com a qual "os homens se encontram limitados nas suas possibilidades de perceberem além das situações limites" (Freire, 1983, p. 30). No reconhecimento desses limites e potencialidades é que a articulação do pensamento de Paulo Freire com a formulação dos espaços estruturais de Boaventura pode representar um campo fértil para se pensar desenvolvimento, saúde e ambiente no nível local, em particular nas propostas e estratégias de promoção da saúde emancipatória.

Uma empreitada que se impõe é a de se repensar tais propostas à luz dos espaços. Cumpre-nos como tarefa elucidar de que desenvolvimento, de que saúde e de que ambiente se trata em cada um dos espaços que estamos analisando e atuando. Estes possivelmente se consolidaram como topos de argumentação, contudo de maneira conflituosa, se confrontados em diferentes espaços. Nas ações de promoção de saúde é preciso estar atento para esses poderes, esses direitos e essas formas de conhecimento, confrontando formas hegemônicas com as não hegemônicas e emancipatórias. Isto se dá com a incorporação dos saberes e práticas cotidianas locais que se baseiam em valores solidários, e não em regulatórios que atendem prioritariamente aos interesses do mercado, da produção e da globalização. Assim, acreditamos aumentar as bases conceituais para se construírem possibilidades de ampliação democrática e de futuros mais saudáveis.

Essas considerações apontam para estratégias de análise das condições de saúde de populações historicamente vulnerabilizadas em termos socioambientais para que se criem as condições de futuro mais saudáveis por meio de processos emancipatórios. A limitação das ações locais reafirma, por sua vez, a necessidade de construirmos formas mais críticas e contextualizadas na produção de conhecimentos e práticas. Para que isso aconteça, consideramos importante o desenvolvimento de metodologias que problematizem a ideia de desenvolvimento único e de conhecimentos monolíticos em torno de práticas regulatórias, de mercado e científicas hegemônicas, descontextualizadas e não solidárias.

Uma estratégia que vislumbramos nessa direção aponta para a mudança de foco nos estudos e projetos de intervenção na realidade. Propomos expandir a análise direcionada exclusivamente a problemas de saúde e ambiente do presente para considerações a respeito do futuro que se almeja para a 
comunidade, dos meios necessários para se alcançar esse futuro e dos problemas que impedem esse futuro de ocorrer. Uma estratégia possível nessa direção é a da construção de "cenários prospectivos" (Marcial e Grumbach, 2006, p. 12) que incorporem simultaneamente saberes e práticas locais com sonhos e esperanças, confrontados por visões críticas acerca dos obstáculos historicamente construídos, bem como por argumentos científicos existentes acerca dos sonhos e cenários. Embora metodologias nessa direção venham sendo utilizadas por organizações para definições estratégicas em contextos de grande incerteza, acreditamos que novas propostas para a construção de cenários poderiam ser desenvolvidas para estudos de realidades locais de forma a incentivar formas criativas e de engajamento no sonho de construção de futuros mais solidários. Nosso objetivo, ao propor tal metodologia, tem caráter didático e pedagógico, na perspectiva freiriana de uma pedagogia da esperança, ao se mudar a perspectiva na análise das questões do dia a dia.

Em nosso caso, ao olhar para o futuro segundo a visão de construção de cenários prospectivos, vislumbra-se o princípio da promoção como o mais evidente, no sentido dado por Czeresnia (2003). A construção de cenários pressupõe a "possibilidade de descrição do que pode ocorrer no futuro com base em hipóteses" plausíveis (Marcial e Grumbach, 2006, p. 12), não sendo uma predição do que irá ocorrer. Ao mesmo tempo, introduz de forma realista o sonho no pensar o território, fornecendo margens ao potencial imaginativo e sonhador, principalmente dos jovens, na produção dos 'inéditos viáveis' de Freire.

No caso dos urbanos, alvo de inúmeros problemas e ações de promoção, a análise da realidade e a construção de cenários necessariamente deveriam envolver e articular temas como o trabalho, a cultura, a saúde, o cuidado com as crianças por meio da educação e das creches, a liberdade de circulação de pessoas, as políticas públicas, o saneamento, o transporte, a poluição, as enchentes e a violência. Tais temas, apesar de já trabalhados na cultura popular de muitas comunidades, continuam sendo desprezados por ações de promoção da saúde e práticas de atenção do Sistema Único de Saúde (SUS) que pensam o futuro a partir somente dos problemas do presente, principalmente orientados por uma visão biomédica do processo saúde-doença, e visões hegemônicas de desenvolvimento que restringem as possibilidades de inéditos viáveis. Em contraste a esta visão de futuro, os cenários prospectivos podem direcionar para uma perspectiva de futuro que incorpore temas tão distintos e interligados no cotidiano das populações vulnerabilizadas que vivem nos territórios periféricos.

No caso dos jovens, a abordagem de cenários pode ser frutífera ao ser aplicada ao trabalho de iniciação científica dessas comunidades por parte de escolas e demais instituições de ensino e pesquisa. Os alunos conhecem bem 
o ambiente e o contexto em que vivem e são capazes de indicar situações problemáticas. Atualmente, a construção de cenários envolve, numa perspectiva corporativa hegemônica, um grupo grande de pessoas (cenaristas e especialistas), exige um empenho dos participantes para diagnósticos e busca de explicações coerentes para confrontar passado, presente e futuro. A priori, estabelece a possibilidade de mudanças e ressalta o protagonismo por parte dos participantes. Transformada por práticas emancipatórias e de construção de autonomia, a construção de cenários deveria ser orientada a aumentar o diálogo e o confronto entre visões científicas e regulatórias com o contexto e os sonhos de outros futuros, mediante um crescente protagonismo dos jovens e da população de cada comunidade em não só contarem, mas construírem suas histórias de forma significativa em conjunto com outras comunidades em processos de emancipação e a sociedade como um todo.

Portanto, acreditamos que com o estudo das possibilidades de futuro poder-se-ia implantar uma mudança radical de enfoque e argumentações contra-hegemônicas, pois a construção de cenários procura tratar da esperança, uma palavra-chave para a emancipação e a autonomia, centrais nas propostas tanto de Boaventura Santos como de Paulo Freire.

\section{Considerações finais}

Dentro do espaço limitado de um artigo, pretendemos ressaltar a importância do trabalho de Boaventura Santos para a Saúde Coletiva, em especial para os teóricos e profissionais que atuam com a promoção da saúde. Por exemplo, na área de Educação e Saúde, as ideias de Boaventura, assim como as de Paulo Freire, têm sido usadas como base para a abordagem conhecida como Construção Compartilhada do Conhecimento. Esta se revela como práxis, entendendo que o conhecimento é algo a ser construído pelos sujeitos em seus locais. A experiência cotidiana, o dia a dia, traz questões que necessitam ser trabalhadas, e que podem e devem ser compreendidas em articulação com ações sociais e coletivas, o que possibilita estabelecer pontes com a própria Saúde Coletiva.

Entretanto, o senso comum das pessoas em seu cotidiano, entendido como Boaventura conceitua, não é suficiente para o entendimento de totalidade. O conhecimento científico pode e deve ser 'utilizado', mas não da forma como normalmente é feito, como conhecimento definitivo, verdadeiro e imutável, nem tampouco hierarquizado ante o conhecimento do senso comum. A partir daí, pode-se construir um conhecimento compartilhado, que é mais do que a cientifização das ações dos indivíduos: um conhecimento em que "todos os sujeitos são docentes de saberes diferentes" (Carvalho, 
Aciole e Stotz, 2000, p. 2. Visto dessa forma, o conhecimento perde seu papel de dominação e de exclusão.

Apesar de ser um dos mais importantes sociólogos da língua portuguesa, o pensamento de Boaventura ainda carece de um aprofundamento nas questões concretas do campo da saúde, seja comprovando a validade de seus pressupostos, seja indagando sobre os seus limites. Como representante da teoria crítica, mas figurando entre aqueles que acreditam que o polo da emancipação não se esgotou (Pereira e Carvalho, 2008), Boaventura partilha com Freire a ideia de que a reconstrução da emancipação passa pelo resgate do concreto na construção do senso comum emancipatório. No universo do pensamento de Boaventura, pontuamos duas questões caras à proposta de uma promoção de saúde emancipatória nos territórios periféricos e nas populações mais excluídas e vulnerabilizadas da sociedade: a primeira reafirmando e, ao mesmo tempo, relativizando os esforços na construção local de ações de promoção da saúde. A segunda projetando possibilidades menos determinísticas de futuro, fugindo da visão monolítica engendrada pela razão proléptica (Santos, 2008b), que abstrai o futuro e dispensa o seu pensar e, mais relevante, o seu engajamento ativo e crítico por parte das pessoas e comunidades. Criar condições de pensar o futuro, aproximando-o do presente, é dar a ele a concretude correspondente, sem a qual nos tornamos prisioneiros da circunstância ou, na melhor das hipóteses, criamos muros de proteção numa visão prevencionista apenas e abolimos as perspectivas das pontes que podem desembocar nos inéditos viáveis do qual nos fala Paulo Freire.

\section{Notas}

1 Professor-pesquisador do Laboratório de Formação Geral na Educação Profissional em Saúde, Escola Politécnica de Saúde Joaquim Venâncio (Labform/EPSJV), Fundação Oswaldo Cruz (Fiocruz), Rio de Janeiro, RJ, Brasil. Doutor em Saúde Pública e Meio Ambiente pela Fundação Oswaldo Cruz. <jairotek@fiocruz.br>

Correspondência: Escola Politécnica de Saúde Joaquim Venâncio, sala 301, Av. Brasil, 4.365, Manguinhos, CEP 21040-360, Rio de Janeiro, RJ, Brasil.

2 Pesquisador titular do Centro de Estudos de Saúde do Trabalhador e Ecologia Humana, Escola Nacional de Saúde Pública Sergio Arouca, Fundação Oswaldo Cruz (Cesteh/Ensp/Fiocruz), Rio de Janeiro, RJ, Brasil. Doutor em Engenharia de Produção pela Coppe - Instituto Alberto Luiz Coimbra de Pós-Graduação e Pesquisa de Engenharia, Universidade Federal do Rio de Janeiro (Coppe/UFRJ). <marcelo.firpo@ensp.fiocruz.br> 


\section{Referências}

AVRITZER, Leonardo. Em busca de um padrão de cidadania mundial. Lua Nova, São Paulo, n. 55-56, p. 30-55, 2002.

CARVALHO, Maria Alice P.; ACIOLI, Sonia; STOTZ, Eduardo N. O processo de construção compartilhada do conhecimento. Paper. Comunicação apresentada no VI Congresso Brasileiro de Saúde Coletiva, Salvador, 2000.

CARVALHO, Maria Alice P.; ACIOLI, Sonia; STOTZ, Eduardo N. O processo de construção compartilhada do conhecimento: uma experiência de investigação científica do ponto de vista popular. In: VASCONCELOS, Eymard M. (Org.). A saúde nas palavras e nos gestos: reflexões da rede de educação popular e saúde. São Paulo: Hucitec, 2001. p. 101-114.

CZERESNIA, Dina. O conceito de saúde e a diferença entre prevenção e promoção. In: CZERESNIA, Dina; FREITAS, Carlos Machado (Orgs.). Promoção da saúde: conceitos, reflexões, tendências. Rio de Janeiro: Editora Fiocruz, 2003

DAHRENDORF, Ralf. Sociedade e liberdade: para uma análise sociológica do presente. Brasília: Editora da Universidade de Brasília, 1981.

DIEGUES, Antônio C.S. Desenvolvimento sustentável ou sociedades sustentáveis: da crítica dos modelos aos novos paradigmas. São Paulo em Perspectiva, São Paulo, v. 6, n. 1-2, p. 22-29, jan./jun. 1992.

FREIRE, Paulo. Ação cultural para a liberdade. 5. ed. Rio de Janeiro: Paz e Terra, 1981.

. Educação como prática da liberdade. 14. ed. Rio de Janeiro: Paz e Terra, 1983.

Pedagogia da esperança. São Paulo: Paz e Terra, 1994.

Pedagogia da autonomia: saberes necessários à prática educativa. 36. ed. São Paulo: Paz e Terra, 1996.
FREITAS, Ana Lúcia S. Pedagogia do inéditoviável: contribuições de Paulo Freire para fortalecer o potencial emancipatório das relações ensinar-aprender-pesquisar. In: COLÓQUIO INTERNACIONAL PAULO FREIRE, 5. Recife, 19 a 22 de setembro de 2005. Disponível em: <www.paulofreire.org.br/asp/ Index.asp>. Acesso em: 12 nov. 2009.

MARCIAL, Elaine C.; GRUMBACH, Raul S. Cenários prospectivos: como construir um futuro melhor. 4. ed. Rio de Janeiro: Editora da FGV, 2006

MARQUES, Luciana R. Democracia radical e democracia participativa: contribuições teóricas à análise da democracia na educação. Revista Educação \& Sociedade, Campinas, v. 29, n. 102, p. 55-78, 2008.

MINAYO, Maria Cecília S. Saúde-doença: uma concepção popular de etiologia. Cadernos de Saúde Pública, Rio de Janeiro, v. 4, n. 4, p. 363-381, 1998.

NUNES, João Arriscado. O resgate da epistemologia. Revista Crítica de Ciências Sociais, Coimbra, n. 80, p. 45-70, 2007.

O'CONNOR, James. Causas naturales: ensayos de marxismo ecológico. México: Siglo XXI, 2001, p. 63

PEREIRA, Marcus A.; CARVALHO, Ernani. Boaventura de Sousa Santos: por uma nova gramática do político e social. Revista Lua Nova, São Paulo, n. 73, p. 45-58, 2008.

PIVETTA, Fátima; PORTO, Marcelo F. Por uma promoção da saúde emancipatória nos territórios urbanos: a proposta do laboratório territorial de Manguinhos. In: CZERESNIA, Dina; FREITAS, Carlos Machado (Orgs.). Promoção da saúde: conceitos, reflexões, tendências. Rio de Janeiro: Editora Fiocruz, 2010.

REIS, Márcio C.. Regulação de conflitos sócioambientais e desenvolvimento: notas a partir das contribuições de Fernand Braudel, Norbert Elias e Boaventura de Sousa Santos. 
Disponível em: <www.ebape.fgv.br/radma/ htm/cadma_sma.htm >. Acesso em: 7 fev. 2007.

RIGOTTO, Raquel M. Saúde ambiental \& Saúde dos trabalhadores: uma aproximação promissora entre o verde e o vermelho. Revista Brasileira de Epidemiologia, Rio de Janeiro, v. 6, n. 4, p. 388-404, 2003.

ROZEMBERG, Brani. O saber local e os dilemas relacionados à validação e aplicabilidade do conhecimento científico em áreas rurais. Cadernos de Saúde Publica, Rio de Janeiro, n. 23, supl. 1, p. s97-s105, 2007.

SANTOS, Boaventura de Sousa. Introdução a uma ciência pós-moderna. Rio de Janeiro: Graal, 1989.

A crítica da razão indolente: contra o desperdício da experiência. São Paulo: Cortez, 2000.

Para além do pensamento abissal: das linhas globais a uma ecologia de saberes. Novos Estudos - Cebrap, São Paulo, n. 79, p. 71-94, 2007.

É chocante a resignação do brasileiro. Entrevista ao Jornal do Brasil (on line). Disponível em: <http://jbonline.terra.com. br/destaques/bienal/entrevista_boaventura _html.> Acesso em: 16 jan. 2008a.

A gramática do tempo: para uma nova cultura política. 2. ed. São Paulo: Cortez, 2008b.

Por uma concepção multicultural de direitos humanos. Disponível em: <www. dhnet.org.br/direitos/militantes/boaventura/ boaventura_dh.htm.> Acesso em: 21 abr. 2010.
SANTOS, Milton. A natureza do espaço. São Paulo: Hucitec, 1997.

SCHÜTZ, Gabriel Eduardo. La insoportable levedad del papel: conflicto socioambiental y salud en torno de la producción de celulosa en el Cono Sur Latinoamericano. Tese (Doutorado em Saúde Pública) - Escola Nacional de Saúde Pública Sergio Arouca, Fundação Oswaldo Cruz (Ensp/Fiocruz), Rio de Janeiro, 2008.

SILVA, Luiz Antonio M. Cidadania, democracia e justiça social. In: SILVA, Luiz Antonio M. et al. (Orgs.). Rio: a democracia vista de baixo. Rio de Janeiro: Ibase, 2004, v. I, p. 25-32.

VALLA, Vitor V. Procurando compreender a fala das classes populares. In: VALLA, Vitor V. (Org.). Saúde e educação. Rio de Janeiro: DP\&A, 2000. p. 11-32.

VIANA, Ana Luiza D'Ávila; ELIAS, Paulo Eduardo M. Saúde e desenvolvimento. Ciência \& Saúde Coletiva [on line], v. 12, supl., p. 1.765-1.777, 2007.

WAGNER, Peter. Sobre guerra e revoluções. In: SANTOS, Boaventura de Sousa (Org.). Conhecimento prudente para uma vida decente. São Paulo: Cortez, 2004. p. 85-102.

Recebido em 17/05/2011

Aprovado em 01/07/2011 